\title{
Multifaceted Role of the Transforming Growth Factor $\beta$ on Effector T Cells and the Implication for CAR-T Cell Therapy
}

\author{
Apolline de Folmont ${ }^{1}$, Jean-Henri Bourhis ${ }^{1,2}$, Salem Chouaib ${ }^{1,3}$ and Stéphane Terry ${ }^{1, *}$ (i) \\ 1 INSERM UMR 1186, Integrative Tumor Immunology and Immunotherapy, Gustave Roussy, Faculty of \\ Medicine, University of Paris Sud, University Paris-Saclay, 94805 Villejuif, France; \\ apolline.dtdf@gmail.com (A.d.F.); jean-henri.bourhis@gustaveroussy.fr (J.-H.B.); \\ salem.chouaib@gustaveroussy.fr (S.C.) \\ 2 Department of Hematology, Gustave Roussy, 94805 Villejuif, France \\ 3 Thumbay Research Institute for Precision Medicine, Gulf Medical University, \\ Ajman 4184, United Arab Emirates \\ * Correspondence: stephane.terry@gustaveroussy.fr
}

Citation: de Folmont, A.; Bourhis, J.-H.; Chouaib, S.; Terry, S.

Multifaceted Role of the

Transforming Growth Factor $\beta$ on Effector T Cells and the Implication for CAR-T Cell Therapy. Immuno 2021, 1, 160-173. https://doi.org/ 10.3390/immuno1030010

Academic Editor: Franco Novelli

Received: 24 April 2021

Accepted: 22 June 2021

Published: 25 June 2021

Publisher's Note: MDPI stays neutral with regard to jurisdictional claims in published maps and institutional affiliations.

Copyright: (c) 2021 by the authors. Licensee MDPI, Basel, Switzerland. This article is an open access article distributed under the terms and conditions of the Creative Commons Attribution (CC BY) license (https:// creativecommons.org/licenses/by/ $4.0 /)$.

\begin{abstract}
Evading the immune system is one of the hallmarks of cancer. Tumors escape antitumor immunity through cell-intrinsic means and the assembly of an immunosuppressive tumor microenvironment. By significantly boosting the host immune system, cancer immunotherapies targeting immune checkpoint receptors (CTLA-4 and PD-1) improved survival in patients even with cancers previously considered rapidly fatal. Nevertheless, an important group of patients is refractory or relapse rapidly. The factors involved in the heterogeneous responses observed are still poorly understood. Other immunotherapeutic approaches are being developed that may widen the options, including adoptive cell therapy using CAR-T cells alone or in combination. Despite impressive results in B cell malignancies, many caveats and unanswered questions remain in other cancers, thus limiting the potential of this approach to treat aggressive diseases. In particular, a complex TME could impair the survival, proliferation, and effector functions of CAR-T cells. Recent reports highlight the potential of targeting TGF- $\beta$ signaling to improve CAR-T cell therapy. TGF- $\beta$ is a well-known regulatory cytokine with pleiotropic effects in the TME, including immunosuppression. This review summarizes recent work investigating the potential effects of TGF- $\beta$ within the TME, with a focus on CAR-T behavior and efficacy. We also discuss several key questions to be addressed to accelerate clinical translation of this approach.
\end{abstract}

Keywords: tumor microenvironment; TGF-beta; CAR-T; lymphocyte; immunotherapy; adoptive T-cell therapy

\section{Introduction}

Evading the immune system is one of the hallmarks of cancer [1]. The tumor microenvironment (TME) of a developing tumor is made of cancer cells and a variety of associated tissue cells, blood vessels, stromal cells, including fibroblast and infiltrating inflammatory cells. The crosstalk between stromal cells and malignant cells within this environment crucially determines the fate of tumor evolution and heterogeneity. This complex network of cells can induce profound immunosuppression. It also participates in tumorigenesis by promoting angiogenesis, invasion, and metastasis. To escape anti-tumor immunity, tumor cells can exploit cell-intrinsic pathways associated with resistance to immune attacks or avoid their recognition by anti-tumor immune cell types. They can also contribute to the assembly of an immunosuppressive through the expression or the secretion of immunosuppressive substances (cytokines, chemokines, etc.) able to inhibit immune effector cells (T cells, NK, DC) while promoting the recruitment and the activation of immunosuppressive cell populations (Tregs, Tumor-Associated Macrophages, MDSCs, etc.) [2]. 
By significantly boosting the host immune system to fight cancer, immunotherapy approaches targeting immune checkpoint receptors (CTLA-4 and PD-1) significantly improved survival in a number of patients even with cancers previously considered rapidly fatal (Melanoma, non-small cell lung cancer (NSCLC), and renal cell carcinoma among others). An important fraction of patients $(20-30 \%)$ is refractory or relapse rapidly [3-6]. The intrinsic resistance of highly prevalent malignancies such as breast, colorectal or prostate cancers also poses a major concern. Understanding the causes of this resistance is a major challenge. Promising approaches are being developed that may widen the spectrum of immunotherapeutic options to overcome resistance. This includes adoptive cell therapy (also referred to as ACT), using CAR-T cells [7]. Various generations of CARs have been developed so far [8-10]. The first-generation CARs are made of an scFv extracellular domain directed against a cell-surface antigen and intracellular $\mathrm{CD} 3 \zeta$ domain, which contains three ITAM motifs. CAR expression on T cells allows recognition of tumor cells via scFv in an MHC-independent manner and their activation [11-13] (Figure 1). In the second and third generations CARs, the intracellular domain was modified to incorporate one or two co-stimulatory domain(s), respectively (e.g., CD28, 4-1BB, OX40, ICOS) (Figure 1). Given this new modification of CARs, the activation of CAR T cells can overcome the absence of natural co-stimulatory signals, further allowing a better activation of the CAR T cells, an increase in the proliferation, cytokine production and survival. Fourth-generation CAR-T cells are designed with a second-generation CAR structure, but in addition, they are armed with inducible cytokines that enable modulating the TME and immune responses. In fact, many different CAR approaches are being explored to overcome exhaustion, improve anti-tumor efficacy and extend their lifespan [9,14]. Different T cell subsets compose the CAR-T population. Each subpopulation can differ in activity, functions, and response to the antigen [15]. Moreover, CD28-based and 4-1BB-based CARs may produce significantly different signals $[13,16]$. It was shown that CD28 CAR T cells expanded more rapidly and typically persisted less in vivo.

CAR-T cell therapy demonstrated spectacular regression in B cell malignancies, although the relapsing disease is still frequent ( $\sim 50 \%$ at 1 year) [7,17-22]. In the case of solid tumors, unfortunately, important caveats and unanswered questions still hamper the use of this approach $[9,23-25]$. In most tumors, the TME is profoundly immunosuppressive. TGF- $\beta$ is viewed as one of the most potent immunosuppressive cytokines in the TME.

The intent of this review is to present recent evidence on the effects of TGF- $\beta$ in the TME and highlight strategies exploiting this pathway to improve the effectiveness of CAR-T-cell therapy. After a brief introduction on the TME and immunosuppression, the role of TGF- $\beta$ on immune effector cells is discussed at both functional and molecular levels. We then summarize recent evidence implicating TGF- $\beta$ in the regulation of CAR-T cells behavior and efficacy. The possible underlying mechanisms at play are discussed, as well as emerging strategies developed to counteract the deleterious effects of TGF- $\beta$. Finally, we discuss the potential limitations of the CAR-T-based approaches and remaining challenges for clinical implementation. 


\section{$1^{\text {st }}$ generation}

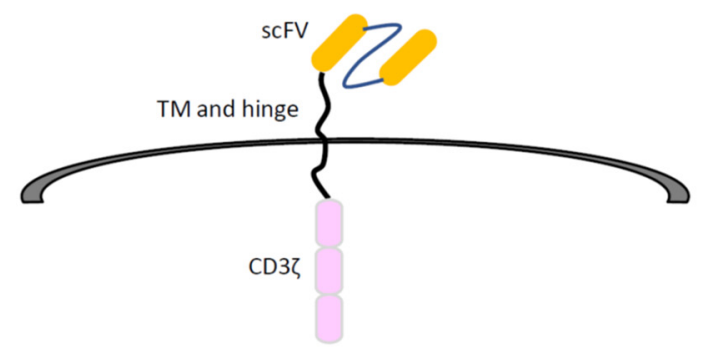

$3^{\text {rd }}$ generation

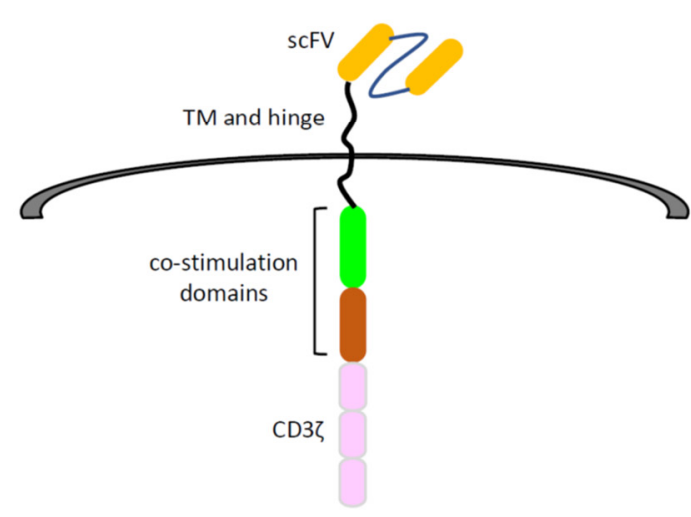

$2^{\text {nd }}$ generation

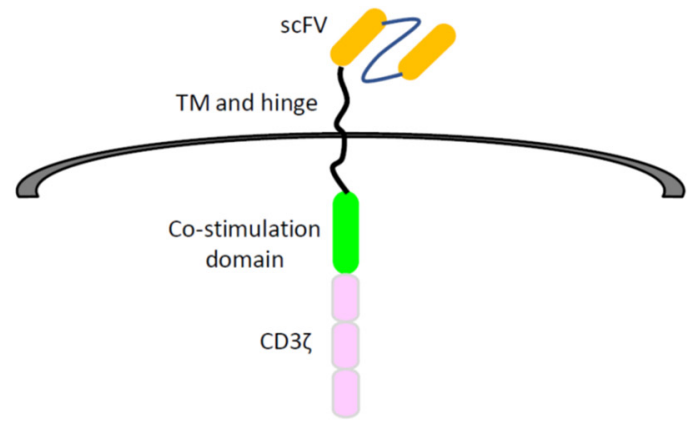

$4^{\text {th }}$ generation

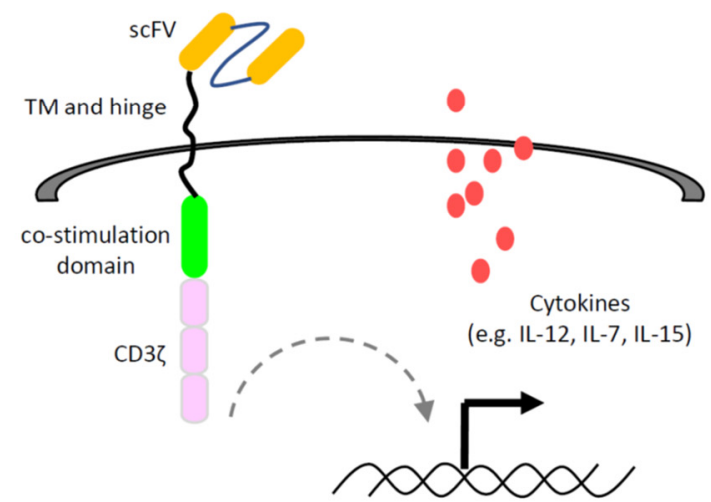

Figure 1. Schematic overview of the main CAR generation formats. The 1st generation CAR is made of an antibody-derived single-chain $\mathrm{Fv}(\mathrm{scFv})$, a hinge and transmembrane (TM) region, and a CD3 $\zeta$ signaling domain. 2nd or 3rd generations contain one or two intracellular co-stimulatory domains linked to $\mathrm{CD} 3 \zeta$, respectively. Costimulatory domain(s) can include CD28, 4-1BB, OX40, and ICOS. The 4th generation resembles the 2nd CAR generation, except it has integrated genetic modifications to induce the production of certain cytokines enabling modulation of immune responses in response to CAR activation.

\section{Tumor Microenvironment and Immunosuppression}

The presence of immunosuppressive cell populations such as tumor-infiltrating myeloid cells, including myeloid-derived suppressor cells (MDSCs) and tumor-associated macrophages (TAMs), especially M2-like TAMs, is known to contribute to immunosuppression [26]. Likewise, the presence of immune regulatory populations, including regulatory T cells (Tregs), Regulatory B cells (Bregs), and Regulatory Dendritic cells (DCregs), can induce profound immunosuppression. Cancer-associated fibroblasts (CAFs) are also involved in immunosuppression, and recent work underlined their essential role in tumor immune escape and resistance to immunotherapy. Importantly, these distinct cell types secrete numerous immunosuppressive substances such as IL10, PGE2, or TGF- $\beta$ in the TME. In general, such factors operate by inhibiting effector functions of anti-tumor immune cells while promoting the differentiation, recruitment, or activity of the different immune suppressor cells [2,26-28].

\subsection{TGF- $\beta$}

TGF- $\beta$ is a cytokine with crucial roles in embryonic development and in adult tissue homeostasis. In cancer, it is recognized as one of the most important regulators in the TME. It can be secreted by tumor cells as well as stromal cells, such as fibroblasts, endothelial 
cells, pericytes, mesenchymal stem cells, lymphatic epithelial cells, as well as by immune cells $[29,30]$.

There are three TGF- $\beta$ ligands: TGF- $\beta 1$, TGF- $\beta 2$, and TGF- $\beta 3$. TGF- $\beta 1$ is the most commonly upregulated in tumor cells and the TME [31-33]. TGF- $\beta$ is released from cells in a latent form consisting of a propeptide (predicted $\sim \mathrm{MW} 30 \mathrm{kDa}$ ) non-covalently associated to the "mature" TGF- $\beta$ sequence (MW $13 \mathrm{kDa}$ ) $[29,33,34]$. The prodomain prevents TGF$\beta$ from binding to TGF- $\beta$ receptors and therefore is called a latency-associated peptide (LAP). The LAP- TGF- $\beta$ complex (often referred to as small latent complex (SLC)) can also bind one of the latent TGF- $\beta$ binding proteins (LTBPs) to form the LTBP-LAP-TGF- $\beta$ complex (referred to as large latent complex (LLC)). Components and enzymes present in the extracellular matrix appear to be essential for processing the latent complexes, thereby controlling the pool of active TGF- $\beta$.

The active TGF- $\beta$ s signal through type I and type II TGF- $\beta$ receptors (TGF- $\beta$ RI and TGF- $\beta$ RII, respectively). TGF- $\beta$ binding to TGF- $\beta$ RII induces heterodimerization with TGF- $\beta$ RI and subsequent phosphorylation and activation of the downstream mediators SMAD2 and SMAD3 [31,34] (Figure 2). Phosphorylated SMAD2/3 can activate and modulate diverse transcriptional programs. Moreover, this signaling pathway can be modulated by numerous TGF- $\beta$ superfamily members allowing complex regulatory loops and crosstalk with other cell signaling pathways [35]. TGF- $\beta$ has pleiotropic effects and can virtually act on all cellular components of the TME. It plays a very important role in tumor initiation and progression [31]. It is widely accepted that TGF- $\beta$ signaling acts as a negative regulator of anti-tumor immunity. Less is known about its role in promoting anti-tumor immunity [30].

\subsection{TGF- $\beta$, TME Components and Immunosuppression}

TAMs can suppress $\mathrm{T}$ cell-mediated anti-tumor immunity by releasing immunosuppressive substances such as TGF- $\beta$, IL-10 and arginase 1 (ARG1) or indoleamine 2,3-dioxygenase (IDO). IDO is an enzyme responsible for metabolizing tryptophan to kynurenine. Metabolic stress depletion through tryptophan depletion may suppress antitumor immunity by preventing the activation of effector $\mathrm{T}$ cells and the inhibition of NK cell activity while promoting the expansion and activation of immature DCs and MDSCs, which, in turn, supports Treg activation [36-38]. Tumor MDSCs can also inhibit tumor immunity through various routes, including the production of IL-10, cyclooxygenase 2 (COX2), arginase 1 (ARG1), TGF $\beta, N O$, and ROS and the induction of Tregs [39]. In tumors, the phenotype of MDSCs often overlaps with those of monocytes and immature neutrophils [29]. CAFs represent another important source of TGF- $\beta$ and have been associated with tumor-growth promoting functions, immunosuppression, and resistance to immunotherapy $[26,40]$. In addition, they can restrain $\mathrm{T}$ cell infiltration and their access to the tumor. TGF- $\beta$ is well-known to promote the polarization of immune cells, including neutrophils, macrophages, and dendritic cells, towards more mature and protumoral phenotypes $[41,42]$. It is worth noting that all these cell components (MDSCs, M2-like macrophages, or CAFs) are not just sources of TGF- $\beta$ s; they seem to exploit autocrine or paracrine TGF- $\beta$ for their expansion, polarization, and behavior towards a tumor-promoting role rather than tumor elimination [29,41-44]. 


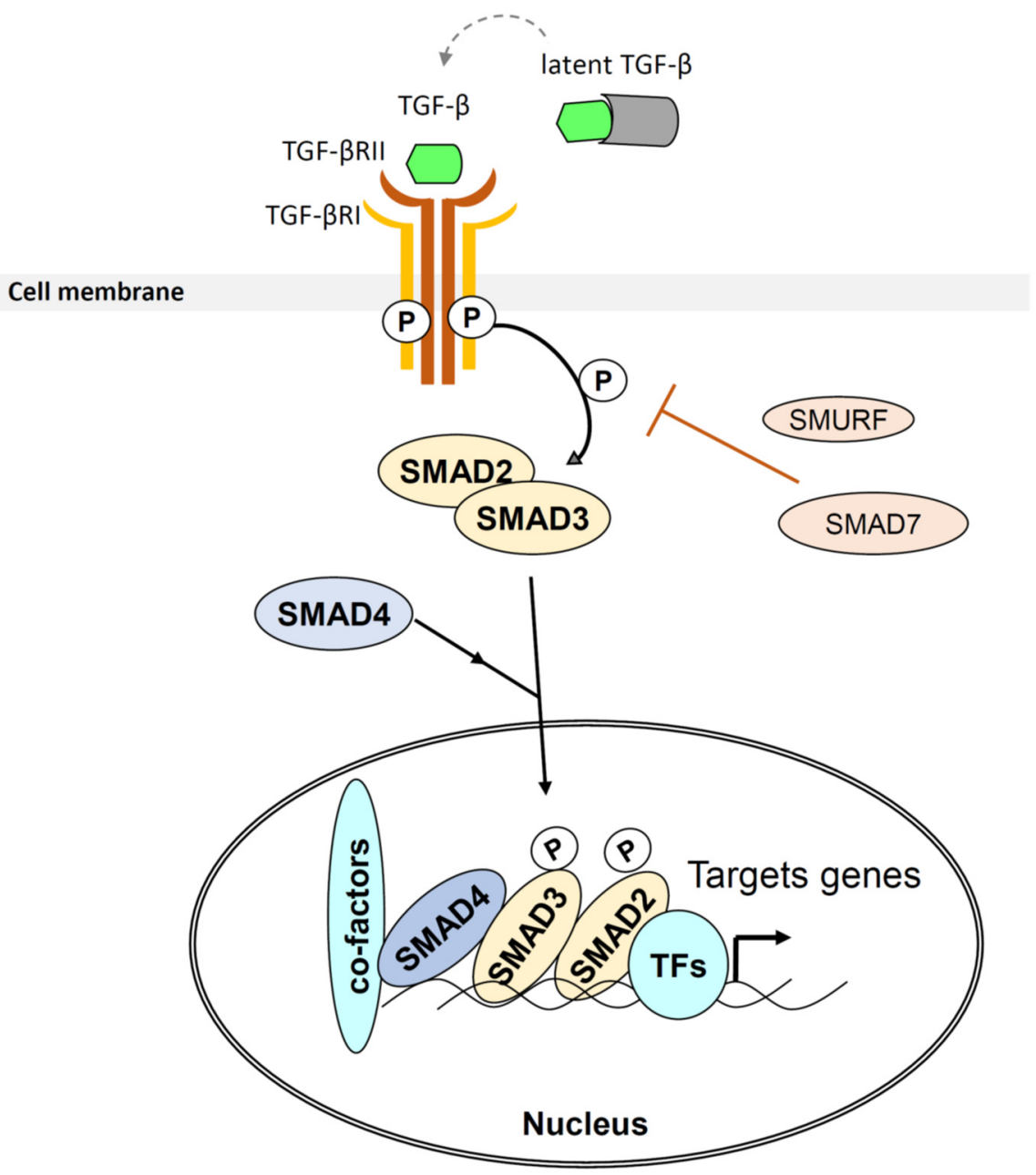

Figure 2. Canonical TGF- $\beta$ signaling through its receptors and SMAD proteins. The release of active TGF- $\beta$ from latent TGF- $\beta$ complex likely involves the action of diverse proteases and interactions with integrins (such as $\alpha \mathrm{v} \beta 6$ or $\alpha \mathrm{v} \beta 8$, not shown). Active TGF- $\beta$ is recognized by the TGF $\beta$ type II receptor at the cell surface. The binding of active TGF- $\beta$ on the receptor further promotes phosphorylation of a type I receptor that dictates the phosphorylation of receptor-regulated SMADs (R-SMADs), such as SMAD2 and SMAD3, which combine with SMAD4 to form R-SMADs-SMAD4 heteromeric complexes able to translocate into the nucleus. These SMAD complexes bind promoters and cooperate with various co-regulators and transcription factors to regulate gene expression. SMAD7, SMURF1, among other factors (not shown), can act in regulatory loops as negative regulators of TGF- $\beta$ signaling.

\section{Effects of TGF- $\beta$ on Effector T Cells and T Regs, and Consequences on Immune Checkpoint Blockade}

TGF- $\beta$ promotes CD4+ T cell differentiation into Treg cells contributing to the suppression of both adaptive and innate immune responses [45,46]. IL-10, as well as TGF$\beta 1$ produced by CD4(+) T FOXP3 cells, may play a role in tumor immune escape and immunosuppression [47]. In the mouse system, it has been reported that TGF- $\beta$ markedly suppresses the cytotoxic function of $\mathrm{CD} 8+\mathrm{T}$ cells through transcriptional downregulation of genes encoding cytotoxic mediators such as perforin, granzymes (GzmA, GzmB), IFN $\gamma$, and FasL [48]. TGF- $\beta$ and IL-10 also inhibit antigen-presenting cells, thus limiting the cytolytic function of tumor-specific T cells. TGF- $\beta$ was found to repress T-cell activation of human $\mathrm{T}$ lymphocytes in the presence of strong $\mathrm{T}$ cell stimuli (anti-CD3/CD28 beads). This was correlated with a decrease in IFN- $\gamma$ and IL-2 secretion and a lower proportion of CD8+ cells expressing GZMB and FASL [49]. Previous work indicates that blockade of endogenous TGF- $\beta$ signaling in T cells using a dominant-negative TGF- $\beta$ RII improves 
anti-tumor responses and tumor control in mice [50,51]. In bladder and colon tumors, microenvironmental TGF- $\beta$ was predictive of poor outcomes $[52,53]$. Among the TGF- $\beta$ isoforms, TGF- $\beta 1$ is primarily expressed in tumors, while TGF- $\beta 3$ is less frequently observed. It is to note that TGF- $\beta 2$ is important for hematopoiesis and cardiac function. This explains in part adverse events and previous failures of pan-TGF- $\beta$ targeting therapies. Thus, diverse targeting agents have been developed to selectively inhibit TGF- $\beta 1$ and/or TGF- $\beta 3$-dependent signaling [54,55].

TGF- $\beta$ has been associated with resistance to immune checkpoint blockade (ICB). Proposed mechanisms include CD8+ T-cell exclusion via stromal remodeling and inhibition of CD4+ T-helper differentiation. Additionally, TGF- $\beta$ signaling induces PD- 1 in antigen-specific tumor-infiltrating lymphocytes (TILs) in a smad-3-dependent manner [56]. Combined inhibition of TGF- $\beta$ and PD-1/PD-L1 signaling may act in synergy to elicit anti-tumor responses and prevent metastasis in various models, including murine mammary (EMT6, 4T1), colon (MC38, LAKTP), cutaneous squamous [57], or pancreatic (KPC1) tumor models [52,53,57-60]; although these tumor models do not respond equally well. Blocking the PD-L1/PD-1 axis and TGF- $\beta$ actions reduced TGF- $\beta$ signaling in stromal cells, facilitated $\mathrm{T}$ cell penetration into the center of the tumor, and provoked vigorous anti-tumor immunity and tumor regression. Additionally, the anti-TGF- $\beta$ /ICB combination can act by suppressing $\mathrm{T}$ regs and inhibiting cancer-associated epithelial-mesenchymal transition [57]. Bifunctional anti-TGF- $\beta$ RII/PD-L1 using bintrafusp alfa (also known as M7824) emerged as a promising strategy for dual targeting of the PD-1/PD-L1 and the TGF- $\beta$ and axis (reviewed recently [61]).

Intriguingly, in the human system, TGF- $\beta$ may be required for retention and maintenance of intratumoral cytotoxic effector cells and tissue-resident memory T cells (TRM). TRM cells may exert key anti-tumor functions coinciding with better disease control and response to immunotherapy [62-65]. It remains unclear whether TGF- $\beta$ s derived from tumoral and stroma areas differentially modulate the activity of these $\mathrm{T}$ cell populations. Nevertheless, the role of certain integrins seems to be critical. Integrins such as $\alpha v \beta 8$ bind and activate latent TGF- $\beta[29,33,66]$. Recent work further suggests $\alpha \nu \beta 8$ as a promising target for cancer immunotherapy [67]. On the other hand, it is now well established that active TGF- $\beta$ is important to induce the expression of $\alpha \mathrm{E} \beta 7$ (CD103) expressed by TRM cells [68]. CD103 endows cells with cytolytic functions and allows binding to E-cadherin expressing tumor cells as well as retention in epithelial tissues [69]. Active TGF- $\beta$ is able to promote CD103-dependent T-cell adhesion and signaling, whereas it inhibits leukocyte function-associated antigen (LFA)-1 ( $\alpha \mathrm{L} \beta 2$ ) integrin expression and LFA-1-mediated T-lymphocyte functions [64]. It is also known that CD8+ T cells can produce TGF- $\beta$ dependent anergy $[70,71]$. A recent study nicely showed that self-production of active TGF- $\beta 1$ allows continuous expression of CD103 on highly cytotoxic T cells without relying on external TGF- $\beta 1$-producing cells [71]. These investigators also noted that integrin $\beta 8$ was specifically upregulated on TGF- $\beta+$ CD103+ cytotoxic T cells (CTLs) isolated from tumor tissues as compared with the CD103- CTLs. CD103+ CTLs had elevated lytic and migration capacity and a slightly increased apoptosis rate. Whether TGF- $\beta$ predisposes certain subpopulations cells to rapid exhaustion warrants further attention. Among the CD103+ TILs, the investigators found certain subpopulations (CD39+) exhibiting a more exhausted phenotype, as assessed by co-expression of different inhibitory receptors (PD-1+, TIM3+, and TIGIT+), whereas others (CD39-) could not demonstrate co-expression of the receptors.

It has also been indicated that under certain circumstances, as in the media supplemented with IL-7 and IL-15, rather than with IL-2, TGF- $\beta$ exposure can confer an early memory phenotype without limiting T-cell expansion. Moreover, this condition did not generate T regs. The proposed mechanism involves BLIMP-1 suppression, which, in turn, results in the induction of ID3, a master regulator of T-cell memory differentiation [72]. Importantly, the data showed that even a brief TGF- $\beta$ exposure could program a durable effect on $\mathrm{T}$ cell expansion and phenotype persistence in vivo. 


\section{Effects of TGF- $\beta$ on CAR-T Effector Functions}

Tumors are heterogenous and dependent on a complex ecosystem formed by the TME. CAR-T cells are widely recognized as a new weapon in the fight against cancer. However, there are many issues to resolve before using the full potential of these living drugs. In their review, Lim W.A. and June C.H. present the major challenges for therapeutic T cells such as (1) trafficking and migrating to the site of the tumor, especially important in the setting of solid tumors, (2) the recognition of tumors and discrimination from healthy cells through the choice of optimal cell surface tumor antigens. (3) the control of mechanisms causing undesirable effects, (4) the proliferation and persistence of these T cells over time, (5) and lastly, overcoming the presence of an immunosuppressive microenvironment while dealing with the tumor heterogeneity [73].

Due to the abundance of TGF- $\beta$ in the TME, its impact on CAR-T cells and the effects of TGF- $\beta$ signaling blockade has been explored [74-78] (Figure 3). The original study of Koehler et al. [74] found that in vitro exposure to active TGF- $\beta$ can alter the proliferation of first-generation CAR-T cells directed against the carcinoembryonic antigen (CEA) on the LS174T colon cancer model. However, it seemed to have minimal if no effects on CAR-T cytolytic activity and IFN- $\gamma$ secretion. Importantly, these investigators demonstrated that CD28 co-stimulation allowed by second-generation CAR makes these $\mathrm{T}$ cells resistant to TGF- $\beta$-mediated repression of $\mathrm{T}$ cell proliferation. CD28- $\zeta$ CAR T cells had superior efficacy compared to $\zeta$ CAR T in eliminating TGF- $\beta$ producing C15A3 tumors (a stable CEA-expressing variant of MC 38) engrafted in mice. Subsequently, this group showed that CAR-T cells expressing a CD28 co-stimulation domain were more adept than those with $4-1 \mathrm{BB}$ co-stimulation to resist this TGF- $\beta$-mediated repression of T cell proliferation. Here again, TGF- $\beta$ had no effect on the cytotoxic function of the 4-1BB- $\zeta$ CAR-T [75].
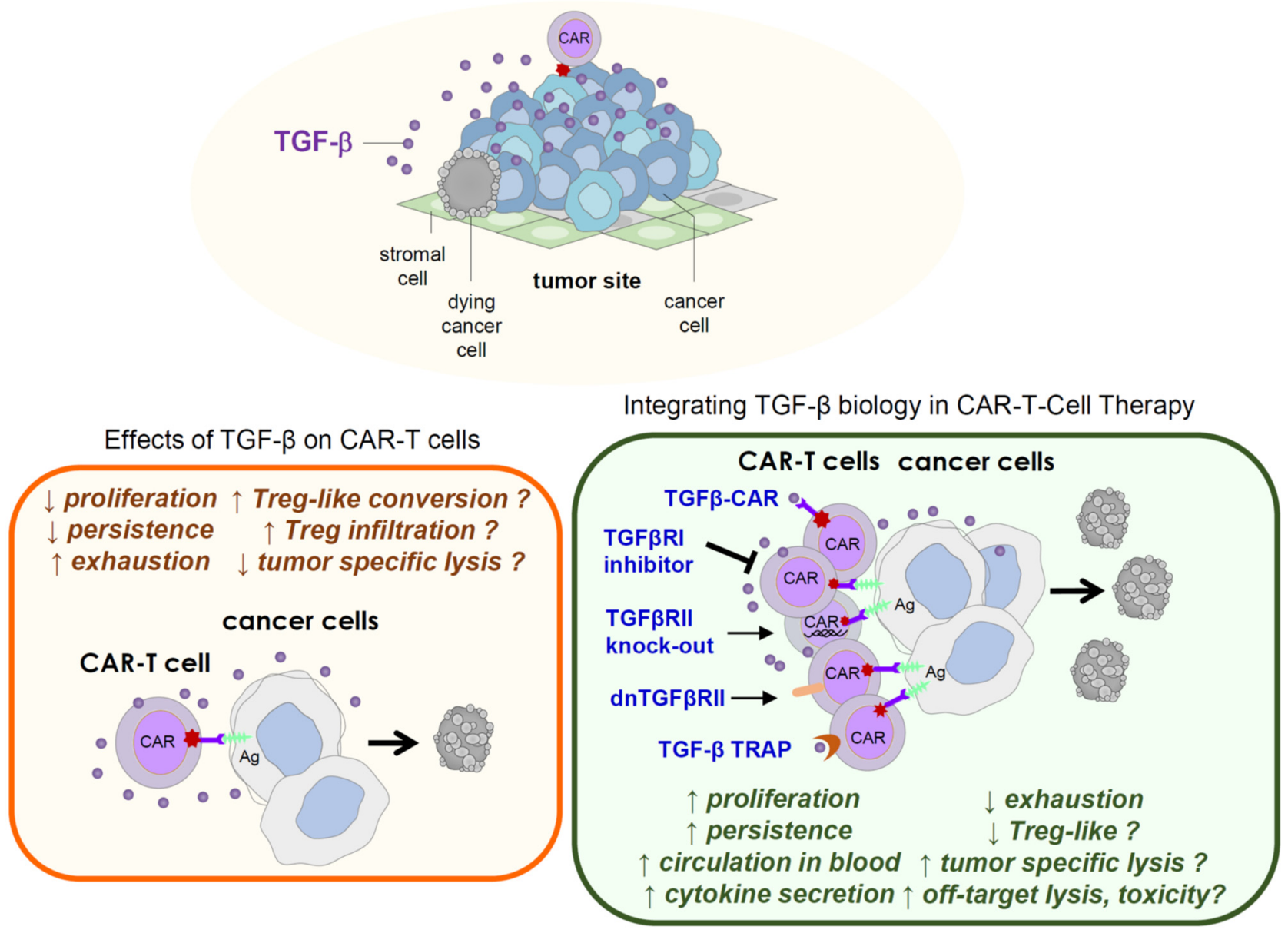

Figure 3. The effects of TGF- $\beta$ on CAR-T cells and targeting of TGF- $\beta$ to improve CAR-T cell therapy. 
The data suggest that CD28 co-stimulation can counteract the deleterious effects of TGF- $\beta$ and that neutralizing TGF- $\beta$ or disrupting TGF- $\beta$ signaling might be particularly beneficial in the setting of therapeutic $\zeta$ CAR-T cells or $4-1 B B-\zeta$ CAR-T cells.

TGF- $\beta$ also inhibited the secretion of IFN- $\gamma$ and IL-2 in $\zeta$, CD28- $\zeta$, and $4-1 B B-\zeta$ CAR-T cells [75]. In fact, the steady-state levels of these cytokines were much higher in the CD28- $\zeta$ CAR-T cells, a characteristic likely due to the CAR CD28 endodomain containing an LCK binding site which supports a positive regulatory loop inducing IL-2 secretion. Thus, the positive regulation of IL-2 can make CD28- $\zeta$ CAR T cells resistant to the suppressive effects of TGF- $\beta$. One potential limitation is that CD28-induced IL-2 production may be counterproductive in vivo since IL-2 in the TME can also sustain tumor-infiltrating Treg cells [74]. For this reason, the investigators studied the potential utility of other cytokines to avoid excessive secretion of IL-2 upon CAR-T activation. IL2 and IL15 promote T-reg but not IL-7 because Treg cells do not express the IL-7R $\alpha$ [79]. IL-7 and IL-15 can replace IL-2 in mediating TGF- $\beta$ resistance of CAR T cells. Moreover, engineered IL- 2 deficient CAR T cells with a hybrid IL-7 $\alpha /$ IL-2R $\beta$ receptor demonstrated in vivo anti-tumor efficacy against C15A3 tumors. IL-7 also augments the amplification of activated T cells and, therefore, may be an interesting supplement to improve amplification and persistence of the CAR-T cells. Intriguingly, in the study from Dahmani et al., BCMA-CD28- $\zeta$ CAR- T cells generated in cultures supplemented with TGF- $\beta$, IL-7, and IL-15 were highly cytotoxic against Myeloma KMS-11 cells, with improved persistence and control of tumor growth in immunodeficient animals compared to CAR-T cells unexposed to TGF- $\beta$ prior to infusion [72]. In the recent report by Tang et colleagues, CD28- $\zeta$ CAR-T cells directed against mesothelin were potent against mesothelin expressing mesothelioma NCI-260 and ovarian OVCAR-3 cell lines in vitro [78]. In vivo, the CAR-T was able to slow down the growth of engrafted tumors in mice compared to vehicle-injected animals [78]. Further work showed TGF- $\beta$ exposure downregulated IL-2 expression in cocultures with CRL5826 cells, at least in the CD4+ population, whereas IFN- $\gamma$ expression was inhibited in both CD4+ and CD8+ cells. Moreover, TGF- $\beta$ inhibited the production of granzymes in cells coinciding with a reduction in tumor-cell-specific lysis [78], which contrasted with other studies [75,76]. Another study using 4-1BB- $\zeta$ CAR-T cells directed against ROR1 found a small but significant reduction of cytotoxic activity in TGF- $\beta$-exposed CAR-T cells cocultured with triple-negative breast cancer MDA-MB-231 cells [77].

Such discrepancies can be explained by the concentrations of IL2 ( 0 to $1000 \mathrm{U} / \mathrm{mL}$ ) and/or TGF- $\beta$ ( $5 \mathrm{ng} / \mathrm{mL}, 10 \mathrm{ng} / \mathrm{mL}$ or more) used during maintenance and activation of the CAR-T before their challenge with the target tumor cells. Other important parameters to consider are the timing conditions, Effector/Target ratios, as well as the type of cytotoxicity assays, used that vary strikingly between studies (i.e., from 4 to $72 \mathrm{~h}$, one vs multiple challenges using various assays (XTT viability assay, Luciferase-based, or chromiumrelease assays). Overall, the direct effect of TGF- $\beta$ on lytic capacity is not fully established and requires clarification. In this context, it will be interesting to see if TGF- $\beta$ can affect immune synapse formation and associated signaling. Another open question is whether TGF- $\beta$ could induce metabolic reprogramming in these cells [80].

In the study of Tang et al., TGF- $\beta$ induced rapid PD-1 upregulation in CAR-T cells, and in the long-term setting, expression of major inhibitory receptors such as LAG3, TIM3, or CTLA- 4 was increased in the TGF- $\beta$ exposed CAR-T cells. This suggested that active TGF- $\beta$ can accelerate the exhaustion of CD28- $\zeta$ CAR-T cells [78]. Another intriguing observation was that TGF- $\beta$ induced a set of Treg-associated genes such as FOXP3, BACH2, HELIOS both in CD8+ and CD4+ T cells, raising the intriguing possibility that TGF- $\beta 1$ induces a Treg-like phenotype. One can speculate that excessive activation of the CD28-IL2 loop, coincident with the high reactivity of CD28- $\zeta$ CAR-T cells, may create the ideal conditions for rapid CAR-T exhaustion and/or acquisition of Treg-like phenotypes while encouraging Tregs infiltration. Nevertheless, this may not be restricted to CD28- $\zeta$ CAR-T cells as downregulation of FOXP3 + cells was likewise observed in 4-1BB- $\zeta$ CAR-T cells forced to express a dominant-negative TGF- $\beta$ RII (dnTGF $\beta$ RII) [76]. As mentioned, the addition of 
active TGF- $\beta 1$ appeared to upregulate the expression of exhaustion markers, such as PD-1, TIM-3, LAG-3, and CTLA-4 in CAR T cells, but without clear data on which cell population express these receptors (that is, CD4+, CD8+ effector cells or Treg-like) [78]. Such effect was found to be reduced in CAR-T expressing dnTGF $\beta$ RII. The latter also performed much better in vivo and could eradicate engrafted tumors in most instances.

\section{Therapeutic Consequences and Considerations}

CAR T cells were engineered to overcome the suppressive effects of TGF- $\beta$ by forcing them to co-express a dominant-negative TGF- $\beta$ RII (dnTGF $\beta$ RII). Kloss C.C. and colleagues applied this approach to 4-1BB- $\zeta$ CAR-T cells targeting the prostate-specific membrane antigen (PSMA) [76]. Exploiting a model of aggressive AR negative prostate cancer (PC3 cells) in vitro and in vivo, they demonstrated increased potency of these CAR-T cells to eradicate these tumor cells. The CAR-T expressing dnTGF $\beta$ RII had improved proliferation and demonstrated enhanced persistence (Figure 3). Blockade of TGF- $\beta$ signaling did not result in significant improvement of cytotoxic capacity toward target cells but instead prevented exhaustion while favoring inflammatory responses and the expression of TH2 cytokines (i.e., IL-4, IL-5, and IL-13), various chemoattractant cytokines (i.e., IP-10, MIP1- $\alpha$, MIP1- $\beta$, and CCL5. No effects were noted on IL-2 secretion.

Two non-randomized clinical studies are ongoing that will assess toxicity and antitumor effects of CART-PSMA-TGF $\beta$ RDN cells in the setting of metastatic castrate-resistant prostate cancers. Primary results are expected in September 2021 (NCT03089203) and November 2022 (NCT04227275).

Other investigators demonstrated that knocking out the endogenous TGF- $\beta$ RII via CRISPR/Cas9 technology can enhance tumor elimination efficacy of CD28- $\zeta$ meso-CAR$\mathrm{T}$ cells toward CRL5826 CDX and PDX deriving from pancreatic human tumors [78]. Combining TGFBR2 suppression with PD-1 inactivation further improved the therapeutic effects of these CAR-T cells. Mechanistically, the authors showed that abrogating TGF- $\beta$ signaling can overcome the effect of TGF- $\beta$ on exhaustion and prevent T-reg-like conversion of CAR-T cells.

In the study from Stuber et al., the TGF- $\beta$ receptor blockade was achieved by using a specific TGFBR1 kinase inhibitor, SD-208. Upon exposure to active TGF- $\beta$, proliferation, cytokine production and viability of ROR1-CAR T-cells were markedly impaired. TGF$\beta$ signaling blockade protects the CAR-T cells from these inhibitory effects supporting anti-tumor activity against MDA-MB-231 TNBC cells in vitro in 2D and 3D cultures. The possibility of treating patients with this type of agent is attractive to control transiently CAR-T cell proliferation, cytokine production while limiting off-target toxicity.

Other investigators have developed CAR-T cells engineered to respond robustly to active TGF- $\beta$ (TGF- $\beta$ CAR-T cells), allowing enhanced anti-tumor efficacy of neighboring cytotoxic $\mathrm{T}$ cells and restrain Treg cell expansion [81,82]. Indeed, TGF- $\beta$ CAR-T cells could significantly improve CD20 CAR-T-mediated lysis against CD20+ Raji cells. They showed that TGF- $\beta$ CAR-T cells reduce the Treg differentiation and suppressive functions of neighboring T cells, while transduction of TGF- $\beta$-CAR itself would not lead to Treg-like differentiation in the CAR-T population. Although one limitation of this technology is that these CAR-T cells are independently active of tumor targeting and against virtually any cell or tissue producing TGF- $\beta$, this approach may aid in some instances to protect neighboring cells from TGF- $\beta$ suppressive effects and promote their anti-tumor function in tumors with substantial TGF- $\beta$ levels. Future studies assessing combinatorial strategies and related toxicities would help address the limitations and determine the optimal conditions for this approach.

Finally, a recent study aimed to neutralize microenvironmental TGF- $\beta$ using EGFRvIIIspecific CAR T cells modified to express TGF $\beta$ RII ectodomain as a TGF- $\beta$-trap. The investigators showed evidence that such modification can enhance anti-tumor efficacy against Glioma U87 cells and murine GL261 in tumor-bearing animals coinciding with prolonged CAR-T survival. The CAR-T cells were also found to modulate the TME since 
the TGF- $\beta$-trap CAR-T's condition was associated with increased M1 polarization of the infiltrated microglia [49].

Despite significant advances in our understanding of the TGF- $\beta$ effects, the high dose of active TGF- $\beta$ supplementation utilized across these studies is questionable. The precise level of active TGF- $\beta$ at the tumor site and in diverse malignancies has been unclear and warrants further investigations. It is noteworthy that Tang and colleagues underlined that TGF- $\beta$ levels secreted by tumor cells were not sufficient to affect CAR-T cell proliferation [78]. As a consequence, a high dose of active TGF- $\beta$ was employed in the in vitro experiments. These observations could reflect the fact that in certain tumors, despite high levels of the latent form, the amount of active TGF- $\beta$ remains limited in the epithelial compartment or at least different compared to the amounts found in the stromal compartments. Studies investigating the process of TGF- $\beta$ maturation in these settings are required [33].

In the study of Kloss et al., no exogenous TGF- $\beta$ was added. Knock-down of the endogenous TGF- $\beta$ signaling in CAR-T cells was clearly beneficial for the eradication of PC3 cells [76]. This could reflect the involvement of tumor- or CAR-T-derived TGF- $\beta$. In this line, the results of Stüber et al. pointed out the importance of TGF- $\beta$ autocrine production and signaling in CAR-T cells [77]. Further investigations may be required to fully characterize TGF- $\beta$ signaling in CAR-T cells. Moreover, because PDX or CDX transplantation in immunodeficient does not fully recapitulate TME, it will be critical for the efforts to develop and study preclinical models that better mimic a suppressive TME. Clearly, generalizations should be avoided, and many aspects deserve clarification before clinical translation. There are other considerations. Despite TGF- $\beta$ is an essential immunosuppressive substance in tumor tissues, other mechanisms and metabolic changes also greatly contribute to immune suppression [83]. Therefore, manipulating TGF- $\beta$ signaling may have a limited impact in some contexts, and combinatorial approaches must be considered.

With increased efficacy, proliferation and persistence of CAR-T cells, one can reasonably question the safety and off-target effects of these approaches. However, in most cases, this aspect has been poorly investigated. One potential limitation is that improved CAR-T functions might enhance non-specific killing, and investigators should devote great care to control these effects in vitro and in vivo. The study of Kloss and colleagues is interesting in this respect [76]. Mock-transduced cells were included in the experiments to control allogeneic effects. Mismatched CD19 CAR were also included to control antigen-independent effects of the CAR-T. This study notably found that groups of mice receiving dnTGF $\beta$ RII CAR T cells developed graft-versus-host disease (GvHD) necessitating euthanasia a month after CAR T cell infusion. This correlated with a higher proportion of human CD3+ cells detected in peripheral blood of the mice. Human T cells in the dnTGFbRII CAR-T were typically 3 to 7 times higher in the blood compared to conventional second-generation CAR-T cells. It remains unknown however if this higher number of circulating CAR-T was simply due to a better proliferation in vivo and/or reduced tumor retention vs improved trafficking in the blood stream [76,78].

\section{Conclusions}

The CAR-T efficacy has revolutionized cancer therapy in hematological malignancies expressing CD19 and CD20 antigens. This enthusiasm has been challenged by a high relapse rate, and for many tumor types, major obstacles such as antigen specificity and the presence of an immune-suppressive environment $[7,21,23,72,83]$. Especially in the case of solid tumors, the full potential of CAR-T cells to eradicate aggressive disease remains to be exploited. Concerns such as therapeutic resistance, safety, and off-target toxicity have to be addressed $[84,85]$. The development of methods to restrain the suppressive effects of TGF- $\beta$ in the TME is promising but requires further exploration of safety and off-target toxicities. Additionally, to our knowledge, there is no data available on CAR-T propensity to traffic and migrate to the tumor site in this setting. Clearly, CAR-T cell therapy should 
benefit from a better understanding of the cellular and molecular basis governing TGF- $\beta$ signaling in CAR-T cells as well as crosstalk with the TME. This should help develop biomarkers of response and improve the control of these newly designed CAR-T cells. Finally, CAR-based strategies beyond T Lymphocytes should be considered [86,87].

Author Contributions: A.d.F., S.T.; writing—original draft preparation, A.d.F., J.-H.B., S.C. and S.T.; writing-review and editing. All authors have read and agreed to the published version of the manuscript.

Funding: Stephane Terry was supported by a grant from ARTP.

Acknowledgments: We are thankful to many colleagues for continuous encouraging discussions, from within and outside Gustave Roussy, Inserm, Université Paris-Saclay, l'Association pour la Recherche sur les Tumeurs de la Prostate, and Cancéropôle Ile-de-France, and give particular thanks to Carl H. June (University of Pennsylvania, USA).

Conflicts of Interest: The authors declare no conflict of interest.

\section{References}

1. Hanahan, D.; Weinberg, R.A. Hallmarks of Cancer: The Next Generation. Cell 2011, 144, 646-674. [CrossRef]

2. Binnewies, M.; Roberts, E.W.; Kersten, K.; Chan, V.; Fearon, D.F.; Merad, M.; Coussens, L.M.; Gabrilovich, D.I.; Ostrand-Rosenberg, S.; Hedrick, C.C.; et al. Understanding the Tumor Immune Microenvironment (TIME) for Effective Therapy. Nat. Med. 2018, 24, 541-550. [CrossRef]

3. Burstein, H.J.; Krilov, L.; Aragon-Ching, J.B.; Baxter, N.N.; Chiorean, E.G.; Chow, W.A.; De Groot, J.F.; Devine, S.M.; DuBois, S.G.; El-Deiry, W.S.; et al. Clinical Cancer Advances 2017: Annual Report on Progress Against Cancer From the American Society of Clinical Oncology. J. Clin. Oncol. 2017, 35, 1341-1367. [CrossRef] [PubMed]

4. Galluzzi, L.; Chan, T.A.; Kroemer, G.; Wolchok, J.D.; Lopez-Soto, A. The Hallmarks of Successful Anticancer Immunotherapy. Sci. Transl. Med. 2018, 10. [CrossRef] [PubMed]

5. Kalbasi, A.; Ribas, A. Tumour-Intrinsic Resistance to Immune Checkpoint Blockade. Nat. Rev. Immunol. 2020, 20, 25-39. [CrossRef] [PubMed]

6. Hegde, P.S.; Chen, D.S. Top 10 Challenges in Cancer Immunotherapy. Immunity 2020, 52, 17-35. [CrossRef] [PubMed]

7. Boyiadzis, M.M.; Dhodapkar, M.V.; Brentjens, R.J.; Kochenderfer, J.N.; Neelapu, S.S.; Maus, M.V.; Porter, D.L.; Maloney, D.G.; Grupp, S.A.; Mackall, C.L.; et al. Chimeric Antigen Receptor (CAR) T Therapies for the Treatment of Hematologic Malignancies: Clinical Perspective and Significance. J. Immunother. Cancer 2018, 6, 137. [CrossRef]

8. Hong, M.; Clubb, J.D.; Chen, Y.Y. Engineering CAR-T Cells for Next-Generation Cancer Therapy. Cancer Cell 2020, 38, 473-488. [CrossRef] [PubMed]

9. Schaft, N. The Landscape of CAR-T Cell Clinical Trials against Solid Tumors-A Comprehensive Overview. Cancers 2020, 12, 2567. [CrossRef]

10. Rafiq, S.; Hackett, C.S.; Brentjens, R.J. Engineering Strategies to Overcome the Current Roadblocks in CAR T Cell Therapy. Nat. Rev. Clin. Oncol. 2020, 17, 147-167. [CrossRef]

11. Watanabe, K.; Kuramitsu, S.; Posey, A.D.J.; June, C.H. Expanding the Therapeutic Window for CAR T Cell Therapy in Solid Tumors: The Knowns and Unknowns of CAR T Cell Biology. Front. Immunol. 2018, 9. [CrossRef] [PubMed]

12. Benmebarek, M.-R.; Karches, C.; Cadilha, B.; Lesch, S.; Endres, S.; Kobold, S. Killing Mechanisms of Chimeric Antigen Receptor (CAR) T Cells. IJMS 2019, 20, 1283. [CrossRef] [PubMed]

13. Lindner, S.E.; Johnson, S.M.; Brown, C.E.; Wang, L.D. Chimeric Antigen Receptor Signaling: Functional Consequences and Design Implications. Sci. Adv. 2020, 6, eaaz3223. [CrossRef] [PubMed]

14. Poorebrahim, M.; Melief, J.; Pico de Coaña, Y.; L Wickström, S.; Cid-Arregui, A.; Kiessling, R. Counteracting CAR T Cell Dysfunction. Oncogene 2021, 40, 421-435. [CrossRef]

15. Golubovskaya, V.; Wu, L. Different Subsets of T Cells, Memory, Effector Functions, and CAR-T Immunotherapy. Cancers 2016, 8, 36. [CrossRef]

16. Long, A.H.; Haso, W.M.; Shern, J.F.; Wanhainen, K.M.; Murgai, M.; Ingaramo, M.; Smith, J.P.; Walker, A.J.; Kohler, M.E.; Venkateshwara, V.R.; et al. 4-1BB Costimulation Ameliorates T Cell Exhaustion Induced by Tonic Signaling of Chimeric Antigen Receptors. Nat. Med. 2015, 21, 581-590. [CrossRef]

17. Majzner, R.G.; Mackall, C.L. Tumor Antigen Escape from CAR T-Cell Therapy. Cancer Discov. 2018, 8, 1219-1226. [CrossRef]

18. Schuster, S.J.; Bishop, M.R.; Tam, C.S.; Waller, E.K.; Borchmann, P.; McGuirk, J.P.; Jäger, U.; Jaglowski, S.; Andreadis, C.; Westin, J.R.; et al. Tisagenlecleucel in Adult Relapsed or Refractory Diffuse Large B-Cell Lymphoma. N. Engl. J. Med. 2019, 380, 45-56. [CrossRef]

19. Locke, F.L.; Ghobadi, A.; Jacobson, C.A.; Miklos, D.B.; Lekakis, L.J.; Oluwole, O.O.; Lin, Y.; Braunschweig, I.; Hill, B.T.; Timmerman, J.M.; et al. Long-Term Safety and Activity of Axicabtagene Ciloleucel in Refractory Large B-Cell Lymphoma (ZUMA-1): A Single-Arm, Multicentre, Phase 1-2 Trial. Lancet Oncol. 2019, 20, 31-42. [CrossRef] 
20. Raje, N.; Berdeja, J.; Lin, Y.; Siegel, D.; Jagannath, S.; Madduri, D.; Liedtke, M.; Rosenblatt, J.; Maus, M.V.; Turka, A.; et al. Anti-BCMA CAR T-Cell Therapy Bb2121 in Relapsed or Refractory Multiple Myeloma. N. Engl. J. Med. 2019, 380, $1726-1737$. [CrossRef]

21. Shah, N.N.; Fry, T.J. Mechanisms of Resistance to CAR T Cell Therapy. Nat. Rev. Clin. Oncol. 2019, 16, 372-385. [CrossRef]

22. Wang, M.; Munoz, J.; Goy, A.; Locke, F.L.; Jacobson, C.A.; Hill, B.T.; Timmerman, J.M.; Holmes, H.; Jaglowski, S.; Flinn, I.W.; et al. KTE-X19 CAR T-Cell Therapy in Relapsed or Refractory Mantle-Cell Lymphoma. N. Engl. J. Med. 2020, 382, 1331-1342. [CrossRef]

23. Li, J.; Li, W.; Huang, K.; Zhang, Y.; Kupfer, G.; Zhao, Q. Chimeric Antigen Receptor T Cell (CAR-T) Immunotherapy for Solid Tumors: Lessons Learned and Strategies for Moving Forward. J. Hematol. Oncol. 2018, 11, 22. [CrossRef] [PubMed]

24. Martinez, M.; Moon, E.K. CAR T Cells for Solid Tumors: New Strategies for Finding, Infiltrating, and Surviving in the Tumor Microenvironment. Front. Immunol. 2019, 10, 128. [CrossRef] [PubMed]

25. Rodriguez-Garcia, A.; Palazon, A.; Noguera-Ortega, E.; Powell, D.J.; Guedan, S. CAR-T Cells Hit the Tumor Microenvironment: Strategies to Overcome Tumor Escape. Front. Immunol. 2020, 11, 1109. [CrossRef] [PubMed]

26. Bejarano, L.; Jordāo, M.J.C.; Joyce, J.A. Therapeutic Targeting of the Tumor Microenvironment. Cancer Discov. 2021, 11, 933-959. [CrossRef] [PubMed]

27. Galon, J.; Bruni, D. Approaches to Treat Immune Hot, Altered and Cold Tumours with Combination Immunotherapies. Nat. Rev. Drug Discov. 2019, 18, 197-218. [CrossRef]

28. Petitprez, F.; Meylan, M.; de Reyniès, A.; Sautès-Fridman, C.; Fridman, W.H. The Tumor Microenvironment in the Response to Immune Checkpoint Blockade Therapies. Front. Immunol. 2020, 11, 784. [CrossRef]

29. Derynck, R.; Turley, S.J.; Akhurst, R.J. TGF $\beta$ Biology in Cancer Progression and Immunotherapy. Nat. Rev. Clin. Oncol. 2021, 18, 9-34. [CrossRef]

30. Tu, E.; Chia, P.Z.C.; Chen, W. TGF $\beta$ in T Cell Biology and Tumor Immunity: Angel or Devil? Cytokine Growth Factor Rev. 2014, 25, 423-435. [CrossRef]

31. Batlle, E.; Massagué, J. Transforming Growth Factor- $\beta$ Signaling in Immunity and Cancer. Immunity 2019, 50, 924-940. [CrossRef] [PubMed]

32. Annes, J.P.; Munger, J.S.; Rifkin, D.B. Making Sense of Latent TGF $\beta$ Activation. J. Cell Sci. 2003, 116, 217-224. [CrossRef]

33. Munger, J.S.; Sheppard, D. Cross Talk among TGF- $\beta$ Signaling Pathways, Integrins, and the Extracellular Matrix. Cold Spring Harb. Perspect. Biol. 2011, 3, a005017. [CrossRef]

34. Liu, S.; Ren, J.; ten Dijke, P. Targeting TGF $\beta$ Signal Transduction for Cancer Therapy. Sig. Transduct. Target. 2021, 6, 8. [CrossRef]

35. Wakefield, L.M.; Hill, C.S. Beyond TGF $\beta$ : Roles of Other TGF $\beta$ Superfamily Members in Cancer. Nat. Rev. Cancer 2013, 13, 328-341. [CrossRef] [PubMed]

36. Noy, R.; Pollard, J.W. Tumor-Associated Macrophages: From Mechanisms to Therapy. Immunity 2014, 41, 49-61. [CrossRef]

37. Zhang, F.; Wang, H.; Wang, X.; Jiang, G.; Liu, H.; Zhang, G.; Wang, H.; Fang, R.; Bu, X.; Cai, S.; et al. TGF- $\beta$ Induces M2-like Macrophage Polarization via SNAIL-Mediated Suppression of a pro-Inflammatory Phenotype. Oncotarget 2016, 7, 52294-52306. [CrossRef] [PubMed]

38. Frumento, G.; Rotondo, R.; Tonetti, M.; Damonte, G.; Benatti, U.; Ferrara, G.B. Tryptophan-Derived Catabolites Are Responsible for Inhibition of T and Natural Killer Cell Proliferation Induced by Indoleamine 2,3-Dioxygenase. J. Exp. Med. 2002, 196, 459-468. [CrossRef] [PubMed]

39. Li, H.; Han, Y.; Guo, Q.; Zhang, M.; Cao, X. Cancer-Expanded Myeloid-Derived Suppressor Cells Induce Anergy of NK Cells through Membrane-Bound TGF-Beta 1. J. Immunol. 2009, 182, 240-249. [CrossRef]

40. Mhaidly, R.; Mechta-Grigoriou, F. Fibroblast Heterogeneity in Tumor Micro-Environment: Role in Immunosuppression and New Therapies. Semin. Immunol. 2020, 48, 101417. [CrossRef]

41. Flavell, R.A.; Sanjabi, S.; Wrzesinski, S.H.; Licona-Limón, P. The Polarization of Immune Cells in the Tumour Environment by TGFbeta. Nat. Rev. Immunol. 2010, 10, 554-567. [CrossRef] [PubMed]

42. Fridlender, Z.G.; Sun, J.; Kim, S.; Kapoor, V.; Cheng, G.; Ling, L.; Worthen, G.S.; Albelda, S.M. Polarization of Tumor-Associated Neutrophil Phenotype by TGF-Beta: “N1" versus "N2" TAN. Cancer Cell 2009, 16, 183-194. [CrossRef] [PubMed]

43. Gratchev, A. TGF- $\beta$ Signalling in Tumour Associated Macrophages. Immunobiology 2017, 222, 75-81. [CrossRef]

44. Cinier, J.; Hubert, M.; Besson, L.; Di Roio, A.; Rodriguez, C.; Lombardi, V.; Caux, C.; Ménétrier-Caux, C. Recruitment and Expansion of Tregs Cells in the Tumor Environment-How to Target Them? Cancers 2021, 13, 1850. [CrossRef] [PubMed]

45. Nakamura, K.; Kitani, A.; Strober, W. Cell Contact-Dependent Immunosuppression by CD4(+)CD25(+) Regulatory T Cells Is Mediated by Cell Surface-Bound Transforming Growth Factor Beta. J. Exp. Med. 2001, 194, 629-644. [CrossRef] [PubMed]

46. Marie, J.C.; Letterio, J.J.; Gavin, M.; Rudensky, A.Y. TGF-Beta1 Maintains Suppressor Function and Foxp3 Expression in CD4+CD25+ Regulatory T Cells. J. Exp. Med. 2005, 201, 1061-1067. [CrossRef]

47. Donkor, M.K.; Sarkar, A.; Li, M.O. Tgf-B1 Produced by Activated CD4(+) T Cells Antagonizes T Cell Surveillance of Tumor Development. Oncoimmunology 2012, 1, 162-171. [CrossRef]

48. Thomas, D.A.; Massagué, J. TGF-Beta Directly Targets Cytotoxic T Cell Functions during Tumor Evasion of Immune Surveillance. Cancer Cell 2005, 8, 369-380. [CrossRef]

49. Li, Y.; Wu, H.; Chen, G.; Wei, X.; Wang, C.; Zhou, S.; Huang, A.; Zhang, Z.; Zhan, C.; Wu, Y.; et al. Arming Anti-EGFRvIII CAR-T With TGF $\beta$ Trap Improves Antitumor Efficacy in Glioma Mouse Models. Front. Oncol. 2020, 10, 1117. [CrossRef] 
50. Gorelik, L.; Flavell, R.A. Immune-Mediated Eradication of Tumors through the Blockade of Transforming Growth Factor-Beta Signaling in T Cells. Nat. Med. 2001, 7, 1118-1122. [CrossRef]

51. Zhang, Q.; Yang, X.; Pins, M.; Javonovic, B.; Kuzel, T.; Kim, S.-J.; Parijs, L.V.; Greenberg, N.M.; Liu, V.; Guo, Y.; et al. Adoptive Transfer of Tumor-Reactive Transforming Growth Factor-Beta-Insensitive CD8+ T Cells: Eradication of Autologous Mouse Prostate Cancer. Cancer Res. 2005, 65, 1761-1769. [CrossRef]

52. Tauriello, D.V.F.; Palomo-Ponce, S.; Stork, D.; Berenguer-Llergo, A.; Badia-Ramentol, J.; Iglesias, M.; Sevillano, M.; Ibiza, S.; Cañellas, A.; Hernando-Momblona, X.; et al. TGF $\beta$ Drives Immune Evasion in Genetically Reconstituted Colon Cancer Metastasis. Nature 2018, 554, 538-543. [CrossRef] [PubMed]

53. Mariathasan, S.; Turley, S.J.; Nickles, D.; Castiglioni, A.; Yuen, K.; Wang, Y.; Kadel III, E.E.; Koeppen, H.; Astarita, J.L.; Cubas, R.; et al. TGF $\beta$ Attenuates Tumour Response to PD-L1 Blockade by Contributing to Exclusion of T Cells. Nature 2018, 554, 544-548. [CrossRef]

54. Yap, T.; Araujo, D.; Wood, D.; Denis, J.-F.; Gruosso, T.; Tremblay, G.; O'Connor-McCourt, M.; Ghosh, R.; Sinclair, S.; Nadler, P.; et al. P856 AVID200, First-in-Class TGF-Beta1 and Beta3 Selective Inhibitor: Results of a Phase 1 Monotherapy Dose Escalation Study in Solid Tumors and Evidence of Target Engagement in Patients. J. Immunother. Cancer 2020, 8 (Suppl. 1), A6.2-A7. [CrossRef]

55. Martin, C.J.; Datta, A.; Littlefield, C.; Kalra, A.; Chapron, C.; Wawersik, S.; Dagbay, K.B.; Brueckner, C.T.; Nikiforov, A.; Danehy, F.T.; et al. Selective Inhibition of TGF $\beta 1$ Activation Overcomes Primary Resistance to Checkpoint Blockade Therapy by Altering Tumor Immune Landscape. Sci. Transl. Med. 2020, 12. [CrossRef]

56. Park, B.V.; Freeman, Z.T.; Ghasemzadeh, A.; Chattergoon, M.A.; Rutebemberwa, A.; Steigner, J.; Winter, M.E.; Huynh, T.V.; Sebald, S.M.; Lee, S.-J.; et al. TGFß1-Mediated SMAD3 Enhances PD-1 Expression on Antigen-Specific T Cells in Cancer. Cancer Discov. 2016, 6, 1366-1381. [CrossRef]

57. Dodagatta-Marri, E.; Meyer, D.S.; Reeves, M.Q.; Paniagua, R.; To, M.D.; Binnewies, M.; Broz, M.L.; Mori, H.; Wu, D.; Adoumie, M.; et al. $\alpha$-PD-1 Therapy Elevates Treg/Th Balance and Increases Tumor Cell PSmad3 That Are Both Targeted by $\alpha$-TGF $\beta$ Antibody to Promote Durable Rejection and Immunity in Squamous Cell Carcinomas. J. Immunother. Cancer 2019, 7, 62. [CrossRef]

58. Horn, L.A.; Riskin, J.; Hempel, H.A.; Fousek, K.; Lind, H.; Hamilton, D.H.; McCampbell, K.K.; Maeda, D.Y.; Zebala, J.A.; Su, Z.; et al. Simultaneous Inhibition of CXCR1/2, TGF- $\beta$, and PD-L1 Remodels the Tumor and Its Microenvironment to Drive Antitumor Immunity. J. Immunother. Cancer 2020, 8. [CrossRef] [PubMed]

59. Sow, H.S.; Ren, J.; Camps, M.; Ossendorp, F.; Ten Dijke, P. Combined Inhibition of TGF- $\beta$ Signaling and the PD-L1 Immune Checkpoint Is Differentially Effective in Tumor Models. Cells 2019, 8, 320. [CrossRef] [PubMed]

60. Holmgaard, R.B.; Schaer, D.A.; Li, Y.; Castaneda, S.P.; Murphy, M.Y.; Xu, X.; Inigo, I.; Dobkin, J.; Manro, J.R.; Iversen, P.W.; et al. Targeting the TGF $\beta$ Pathway with Galunisertib, a TGF $\beta$ RI Small Molecule Inhibitor, Promotes Anti-Tumor Immunity Leading to Durable, Complete Responses, as Monotherapy and in Combination with Checkpoint Blockade. J. Immunother. Cancer $2018,6,47$. [CrossRef]

61. Lind, H.; Gameiro, S.R.; Jochems, C.; Donahue, R.N.; Strauss, J.; Gulley, J.L.; Palena, C.; Schlom, J. Dual Targeting of TGF- $\beta$ and PD-L1 via a Bifunctional Anti-PD-L1/TGF-BRII Agent: Status of Preclinical and Clinical Advances. J. Immunother. Cancer 2020, 8. [CrossRef] [PubMed]

62. Mami-Chouaib, F.; Blanc, C.; Corgnac, S.; Hans, S.; Malenica, I.; Granier, C.; Tihy, I.; Tartour, E. Resident Memory T Cells, Critical Components in Tumor Immunology. J. Immunother. Cancer 2018, 6, 87. [CrossRef] [PubMed]

63. Amsen, D.; van Gisbergen, K.P.J.M.; Hombrink, P.; van Lier, R.A.W. Tissue-Resident Memory T Cells at the Center of Immunity to Solid Tumors. Nat. Immunol. 2018, 19, 538-546. [CrossRef] [PubMed]

64. Boutet, M.; Gauthier, L.; Leclerc, M.; Gros, G.; de Montpreville, V.; Theret, N.; Donnadieu, E.; Mami-Chouaib, F. TGFbeta Signaling Intersects with CD103 Integrin Signaling to Promote T-Lymphocyte Accumulation and Antitumor Activity in the Lung Tumor Microenvironment. Cancer Res. 2016. [CrossRef] [PubMed]

65. Corgnac, S.; Malenica, I.; Mezquita, L.; Auclin, E.; Voilin, E.; Kacher, J.; Halse, H.; Grynszpan, L.; Signolle, N.; Dayris, T.; et al. CD103+CD8+ TRM Cells Accumulate in Tumors of Anti-PD-1-Responder Lung Cancer Patients and Are Tumor-Reactive Lymphocytes Enriched with Tc17. Cell Rep. Med. 2020, 1, 100127. [CrossRef]

66. Brown, N.F.; Marshall, J.F. Integrin-Mediated TGF $\beta$ Activation Modulates the Tumour Microenvironment. Cancers 2019, $11,1221$. [CrossRef]

67. Dodagatta-Marri, E.; Ma, H.-Y.; Liang, B.; Li, J.; Meyer, D.S.; Sun, K.-H.; Ren, X.; Zivak, B.; Rosenblum, M.D.; Headley, M.B.; et al. Integrin $\mathrm{Av} \beta 8$ on T Cells Is Responsible for Suppression of Anti-Tumor Immunity in Multiple Syngeneic Models and Is a Promising Target for Tumor Immunotherapy. bioRxiv 2020. Available online: https://www.biorxiv.org/content/10.1101/2020.05. 14.084913v1.full (accessed on 30 March 2021).

68. Mokrani, M.; Klibi, J.; Bluteau, D.; Bismuth, G.; Mami-Chouaib, F. Smad and NFAT Pathways Cooperate to Induce CD103 Expression in Human CD8 T Lymphocytes. J. Immunol. 2014, 192, 2471-2479. [CrossRef] [PubMed]

69. Le Floc'h, A.; Jalil, A.; Vergnon, I.; Le Maux Chansac, B.; Lazar, V.; Bismuth, G.; Chouaib, S.; Mami-Chouaib, F. Alpha E Beta 7 Integrin Interaction with E-Cadherin Promotes Antitumor CTL Activity by Triggering Lytic Granule Polarization and Exocytosis. J. Exp. Med. 2007, 204, 559-570. [CrossRef]

70. Baas, M.; Besancon, A.; Goncalves, T.; Valette, F.; Yagita, H.; Sawitzki, B.; Volk, H.D.; Waeckel-Enee, E.; Rocha, B.; Chatenoud, L.; et al. TGFbeta-Dependent Expression of PD-1 and PD-L1 Controls CD8(+) T Cell Anergy in Transplant Tolerance. eLife 2016, 5, e08133. [CrossRef] 
71. Abd Hamid, M.; Colin-York, H.; Khalid-Alham, N.; Browne, M.; Cerundolo, L.; Chen, J.-L.; Yao, X.; Rosendo-Machado, S.; Waugh, C.; Maldonado-Perez, D.; et al. Self-Maintaining CD103+ Cancer-Specific T Cells Are Highly Energetic with Rapid Cytotoxic and Effector Responses. Cancer Immunol. Res. 2020, 8, 203-216. [CrossRef]

72. Dahmani, A.; Janelle, V.; Carli, C.; Richaud, M.; Lamarche, C.; Khalili, M.; Goupil, M.; Bezverbnaya, K.; Bramson, J.L.; Delisle, J.-S. TGF $\beta$ Programs Central Memory Differentiation in Ex Vivo-Stimulated Human T Cells. Cancer Immunol. Res. 2019, 7, 1426-1439. [CrossRef] [PubMed]

73. Lim, W.A.; June, C.H. The Principles of Engineering Immune Cells to Treat Cancer. Cell 2017, 168, 724-740. [CrossRef]

74. Koehler, H.; Kofler, D.; Hombach, A.; Abken, H. CD28 Costimulation Overcomes Transforming Growth Factor-Beta-Mediated Repression of Proliferation of Redirected Human CD4+ and CD8+ T Cells in an Antitumor Cell Attack. Cancer Res. 2007, 67, 2265-2273. [CrossRef] [PubMed]

75. Golumba-Nagy, V.; Kuehle, J.; Hombach, A.A.; Abken, H. CD28- $\zeta$ CAR T Cells Resist TGF- $\beta$ Repression through IL-2 Signaling, Which Can Be Mimicked by an Engineered IL-7 Autocrine Loop. Mol. Ther. 2018, 26, 2218-2230. [CrossRef]

76. Kloss, C.C.; Lee, J.; Zhang, A.; Chen, F.; Melenhorst, J.J.; Lacey, S.F.; Maus, M.V.; Fraietta, J.A.; Zhao, Y.; June, C.H. DominantNegative TGF- $\beta$ Receptor Enhances PSMA-Targeted Human CAR T Cell Proliferation And Augments Prostate Cancer Eradication. Mol. Ther. 2018, 26, 1855-1866. [CrossRef]

77. Stüber, T.; Monjezi, R.; Wallstabe, L.; Kühnemundt, J.; Nietzer, S.L.; Dandekar, G.; Wöckel, A.; Einsele, H.; Wischhusen, J.; Hudecek, M. Inhibition of TGF- $\beta$-Receptor Signaling Augments the Antitumor Function of ROR1-Specific CAR T-Cells against Triple-Negative Breast Cancer. J. Immunother. Cancer 2020, 8. [CrossRef]

78. Tang, N.; Cheng, C.; Zhang, X.; Qiao, M.; Li, N.; Mu, W.; Wei, X.-F.; Han, W.; Wang, H. TGF- $\beta$ Inhibition via CRISPR Promotes the Long-Term Efficacy of CAR T Cells against Solid Tumors. JCI Insight 2020, 5. [CrossRef]

79. Perna, S.K.; Pagliara, D.; Mahendravada, A.; Liu, H.; Brenner, M.K.; Savoldo, B.; Dotti, G. Interleukin-7 Mediates Selective Expansion of Tumor-Redirected Cytotoxic T Lymphocytes (CTLs) without Enhancement of Regulatory T-Cell Inhibition. Clin. Cancer Res. 2014, 20, 131-139. [CrossRef]

80. Rostamian, H.; Fallah-Mehrjardi, K.; Khakpoor-Koosheh, M.; Pawelek, J.M.; Hadjati, J.; Brown, C.E.; Mirzaei, H.R. A Metabolic Switch to Memory CAR T Cells: Implications for Cancer Treatment. Cancer Lett. 2021, 500, 107-118. [CrossRef] [PubMed]

81. Hou, A.J.; Chang, Z.L.; Lorenzini, M.H.; Zah, E.; Chen, Y.Y. TGF- $\beta$-Responsive CAR-T Cells Promote Anti-Tumor Immune Function. Bioeng. Transl. Med. 2018, 3, 75-86. [CrossRef]

82. Chang, Z.L.; Lorenzini, M.H.; Chen, X.; Tran, U.; Bangayan, N.J.; Chen, Y.Y. Rewiring T-Cell Responses to Soluble Factors with Chimeric Antigen Receptors. Nat. Chem. Biol. 2018, 14, 317-324. [CrossRef]

83. Bader, J.E.; Voss, K.; Rathmell, J.C. Targeting Metabolism to Improve the Tumor Microenvironment for Cancer Immunotherapy. Mol. Cell 2020, 78, 1019-1033. [CrossRef]

84. Brudno, J.N.; Kochenderfer, J.N. Recent Advances in CAR T-Cell Toxicity: Mechanisms, Manifestations and Management. Blood Rev. 2019, 34, 45-55. [CrossRef] [PubMed]

85. Kennedy, L.B.; Salama, A.K.S. A Review of Cancer Immunotherapy Toxicity. CA Cancer J. Clin. 2020, 70, 86-104. [CrossRef] [PubMed]

86. Rotolo, R.; Leuci, V.; Donini, C.; Cykowska, A.; Gammaitoni, L.; Medico, G.; Valabrega, G.; Aglietta, M.; Sangiolo, D. CAR-Based Strategies beyond T Lymphocytes: Integrative Opportunities for Cancer Adoptive Immunotherapy. Int. J. Mol. Sci. 2019, $20,2839$. [CrossRef] [PubMed]

87. Liu, E.; Marin, D.; Banerjee, P.; Macapinlac, H.A.; Thompson, P.; Basar, R.; Nassif Kerbauy, L.; Overman, B.; Thall, P.; Kaplan, M.; et al. Use of CAR-Transduced Natural Killer Cells in CD19-Positive Lymphoid Tumors. N. Engl. J. Med. 2020, 382, 545-553. [CrossRef] [PubMed] 